\title{
Unfolding Evolution Strategically in Integrated Studios of Building and Design to Innovative Grasp of Design Creativity
}

\author{
Didem Bas Yanarates \\ Department of Interior Architecture, Fine Arts Faculty, Cukurova University, Adana 01180, Turkey
}

\begin{abstract}
In emergence of design, it is undoubted to be informed from nature for how things get done. But in architecture, the students are not used to start up with biological investigation. Instead of analogues, it is permitted to pursue an evolvability systematics for built emerge. The systematics relies upon the key assumptions of Kirschner who sought the characteristics of biological evolution. For an integrated design thinking of an architectural mind, this is a methodological study, which strategically adapts living forms' evolvability capacity to built-forms' structural emergence. The study outlines the evolution strategy with experimental studios of building and design. The preceding systematic is taught in distinguished courses. It is purposed to build an easy-to-apply framework for how to generate novel structures and how the spatial structure units are organized to emerge with an imagined nature as novel tectonic model. Besides, building up structural thinking into the consilience of evolution strategy, the study is also distinguished for understanding the value system of architectural mind to diagnose the genuine character of inventive built form. Strategy constructs processes. Thinking strategy concludes by the evolvability directives of studio assignments and they are given as flow-charts and project models.
\end{abstract}

Key words: Creativity, innovative design, evolvability, building and design teaching.

\section{Introduction}

Worldwide design agenda focuses on strategies and their systematics for serving to optimize the steep tasks of design thinking. They are utilized to build a bridge between practical settings of design labour and academic settings of teaching and researches. Leatherbarrow, D. [1] observes a contradiction in terms of design and research, and admittedly poses that each activity would seem to have different objects, methods and times. Although the objects of design comprise bringing something new into being, they already exist in hypothesis for the research. And they are presumed at the beginning of the investigation.

Furthermore, Moussavi, F. [2] underlines that architects can embed the environment with differencein two ways: by producing different kinds of ideas for built forms and by exploring different ways of

Corresponding author: Didem Bas Yanarates, Ph.D., main research field: design methods in architecture. actualizingideas as built forms. And she states that current architectural investigations mostly focused on internal geometrical variations of forms, rarely focused on how the ideas they embed differ from other ideas or how the built forms they produce differ from other built forms. Regarding all these considerations, the hard work in case of this study was to incorporate evolution strategically in each studio of building and design intandem as dual processing of design teaching. Consequently, this can be considered as an attempt to develop a systematics with easy-flow logic of evolution which achieve to challenge in understanding:

- How innovative form emerges and its structure is generated;

- How the genuine character of emergent building is invented and why this character makes sense than others.

This crucial understanding is unified in value system of designer's architectural mind, where the 
concerns of how designer generates and how designer's awareness arises, have to be overcome in building and design studios. This study does not comprise the derivations of living forms which were chosen from nature for biomimicry modelling at studios. On the other hand, it is distinguished by using biological evolution strategically. It frames an embodied value system to inform in emergence of structure and design. Based on this challenge, the assignments of integrated studios as building and design were developed on very base algorithmic mind of how nature thinks and gets things done.

Biology has its architecture of emergence. And the shelters which are inherently built by the animals, the bodies of life forms where the plants have privilege, give outcomes-models of novel structures. Each of them has architectural capacity for process of bio-mimetic thinking as being a particular case study. Actually architects know, beginning to design with a natural case study investigation requires experiences in the field of biology. But it necessitates a peculiar biological survey pragmatically for what designers and design students are not expected to be qualified. This state puts them into contradiction and they encounter with a big challenge. As a natural consequence, the architectural mind of designer works fluently to invent, not to construe within a diverge thinking. The way of nature to invent is evolution, and design issues concern to strike a balance with evolutionary novelty. Therefore, in quest of design education for thinking strategy, this study frames parallelism with characteristics of biological evolution and emergence of built-form. It is purposed to bring a qualification to check and verify for structural models and prototypes as the embodiments of novel forms. Those forms are experimentally developed at the studios of building-construction and design courses.

\section{Unfolding Evolution Strategy}

At the art school, the basic design education relies upon an artistic conscious arising in such responses to environmental stimuli. Observation is the essence of teaching task in order to find rapport between constituent and constitutional embodiment. Simply, it means that each observed object lives with its surrounding and a trained eye can detect this symbiotic relation.

The trained eye requires comprehensive glance that grabs clues for what makes an object to survive in emergence of architecture. This is a big challenge of design students. It makes them inevitably to inform from the distinguished fields of science and art. Furthermore, the natural sciences such as biology, physics and chemistry, at the focus of emergence concern, are highly regarded research fields. Those are also the fields to challenge either, where the most cases are not close to be identified by designer. Julian Vincent [3] has distinguished studies in biomimetics and one of his essay on "how can biology inform architect?" underlines the reciprocal challenging of architecture with biology. The main difficulty arises from the way of finding inherent problem in emergence. In natural sciences, it is known where it has to be looked with a trained eye and appreciate the problems of survival. So, it can be more suitable to arrive at progressive study on natural emerges and living organisms as given answers of definite problems regarding them to evolve. Biologists are used to study in this way but designers are not. They need more access of biological skills of translation in order to call for such strategic thinking in evolution. Vincent, J. [3] reveals this difficulty through the misapprehension cases from architecture history and their stories were come to play bybiomorphic elements but apparently differed from bio-mimetic representations.

The need of generating structure and design makes the inventive thinking to meet at a common stratum of evolvability capacity. That meeting point is to construct the emergence of architecture a show nature works. And crucially, it leads designers and researcher 
architects, such as Michael Weinstock [4] and Michael Hensel U. [5], informed from the foremost academic biologists of the millennium who have been peer into the concerns of the design thinking for incorporating the rules of biological evolution. Mark Kirschner [6] - an important name among those biologists, brought the characteristics of evolvability into the field and assigned strategies to articulate for design thinking.

Mark Kirscher's strategy grounds the essential questions of novel varieties and random mutations arises of how much novelty and how much conservation is in the genomes of various organisms. Underlying, the so few genes humans have (about 21,000 genes) which is less than 1.5 times as many as a fruit fly and six times found in a bacterium, humans also have hundreds of trillions of cells as a complex anatomical organization. His enduring sum up of the modern theory of evolution is that humans have the few genes they are shared with very distantly related organisms such as 25 percent with yeast and 50 percent with flies.

Evolution process on genetic variation of individuals is in a population. Thereby, the fittest takes the properties where are inherited through from the preliminary of the place to the environment has been evolved in time. The fitting selection makes the phenotype as the basis of anatomy, physiology and behaviour, meanwhile, the genotype as a set of instruction that makes those basis. The random mutation of diversification has been processing on differences arise in similar environment's population as tremendous amounts of varied organisms. And the diversification changes the genes in time due to the right combination of qualities. As sharing common gene formed the most primitive organism at the origin of life, the types having complex cell metabolism emerged with the structure have the ability to be modified.

What is behind of this novelty? Which way has to be followed to allow innovative emergence of evolution? Kirschner, M. [6] focused on these concerns and sum up the three characteristics of evolution as:

- maximizing variation in the amount of variation;

- suppressing the fallacy of variation produced;

- the provision of useful variation.

The first characteristic of evolution process that Kirschner put is to maximize variations in the amount of mutation. Kirschner's second aspect of evolvability is to suppress the fallacy of variation produced.

The third characteristic is the provision of useful variation, even for conditions not previously encountered, although it may seem strange that the variation is somehow biased to some satisfy conditions it has never seen before [6].

Focusing on these concerns allows to advance the design ability and skills resting upon the innovative capacity of evolvability in order to achieve thinking in competitive level. From this point onward, the strategic characteristics are inquired to construe in fulfilments of both studios of building and design. Therefore, this is to mean appropriation of evolvability into design.

\section{Appropriation of Evolvability to Integrate Building and Design Teaching}

Appropriation of evolvability describes the way to build and design from a source of ideas that has benefited from a 3.8 billion year strategy to vary new and emerge in novelty.

With regard to quest of novel varieties and random mutation, the primary mechanism can be basically suggested with the processes. They operate to generate primitive organisms and evolve them for multicellular organisms and complex novel structure which are drifted to random mutations. That proceeding mainly involves in key-notions of variation, diversification and modification. Articulating in architectural mind for emerge of built-structures the processes are going to conceptualize as variation-transformation and adaptation (Fig. 1). Fig. 1 illustrates how to follow the 


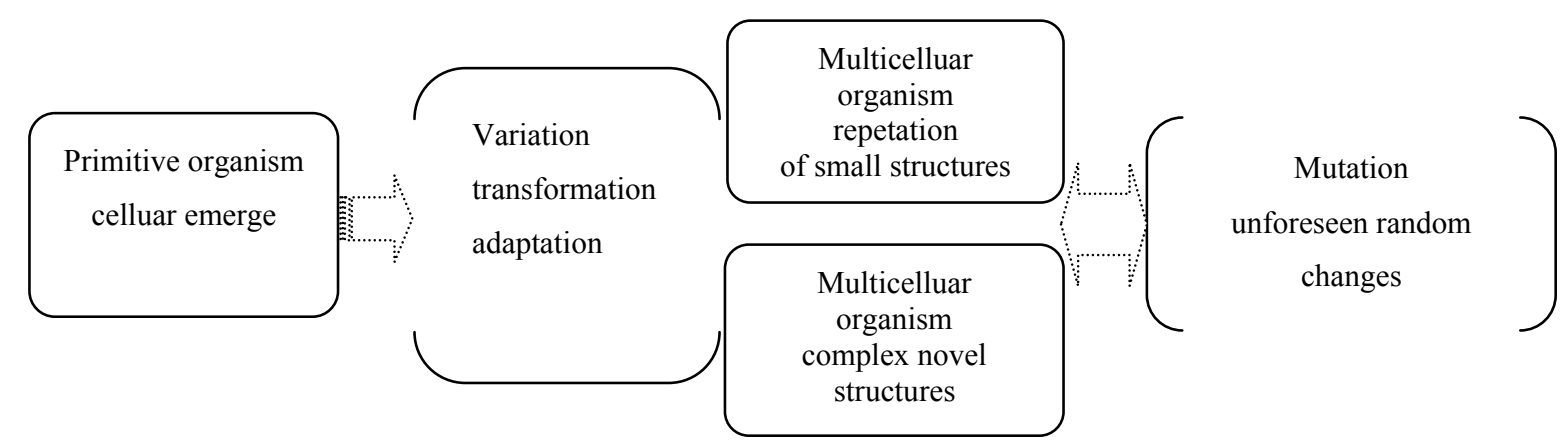

Fig. 1 Following path of evolution, the emergence of primitive organism has to complete process' stages of variation, transformation and adaptation.

path of evolution from the start-up point of cellular emerge to diverse into two structures and reaching the final emergent of mutation, which having learning capacity to survive at unforeseen random changes.

Those processes of evolvability are operating to determine emergent-building structures having genuine characteristic and come to a decision on them "why" they make sense than others. Actually, defining strategy processes in that way facilitates designers and students to use an operative tool for construing what if their project proposals proceed to. That proceeding, in fact, would define their project proposals beginning from the emergence of cell unit as structurally the smallest base unit allows to be maximized in variation.

The following proposal would be transformation of those cellular units to multi-cellular complex structures as to emerge through complex novel structures. Such process incorporates modified pattern of structures in emergence of design products involving all components of architectural design constitution. This implies that random variations have to be considered to eliminate lethal structures and like so, suppress the fallacy of variation preliminary produced facilitates the emergence of hybrid design.

Assembly pattern structures of building studio follows modular pattern of design studio's project to become integrated thinking for innovation of built environment. That not only addresses provision of useful pattern which can be progressively produced but also requires provision of autonomous nature which is emerged in tandem. So, design studio imposes to make tectonic model of derived natureidentified with the built form, where an adaptation process has to be preceded. Conceptually, for design studio adaptation means to yield novel nature for the optimal form of novel design.

In this universe, difference is not fundamentally a property of particular units but a transformation or set of transformations to group what Manuel De Landa calls "progressive differentiation" [7, 8]. Fig. 2 illustrates appropriation of evolvability by coordinating the characteristics of evolvability for nature to invent and the articulation of evolvability for architectural mind to invent.

\section{The Open-mind Systematic to Formulate Questions Instead of Starting with Answers}

One of the most difficult pedagogical problems for the student is to start exploring process of design-solving structures emerged on a set of questions, which have related to the concerns of given task. Given the importance of this difficulty, the guidelines of decision-making are developed by "why" and "how" questions for framing an attitude for easy-apply answers.

With this respect, each project both for building and design studios is going to be constructed in students' mind by framing in quest for the questions "why will it be done?", "how will it be done?" and "what will be done?". 

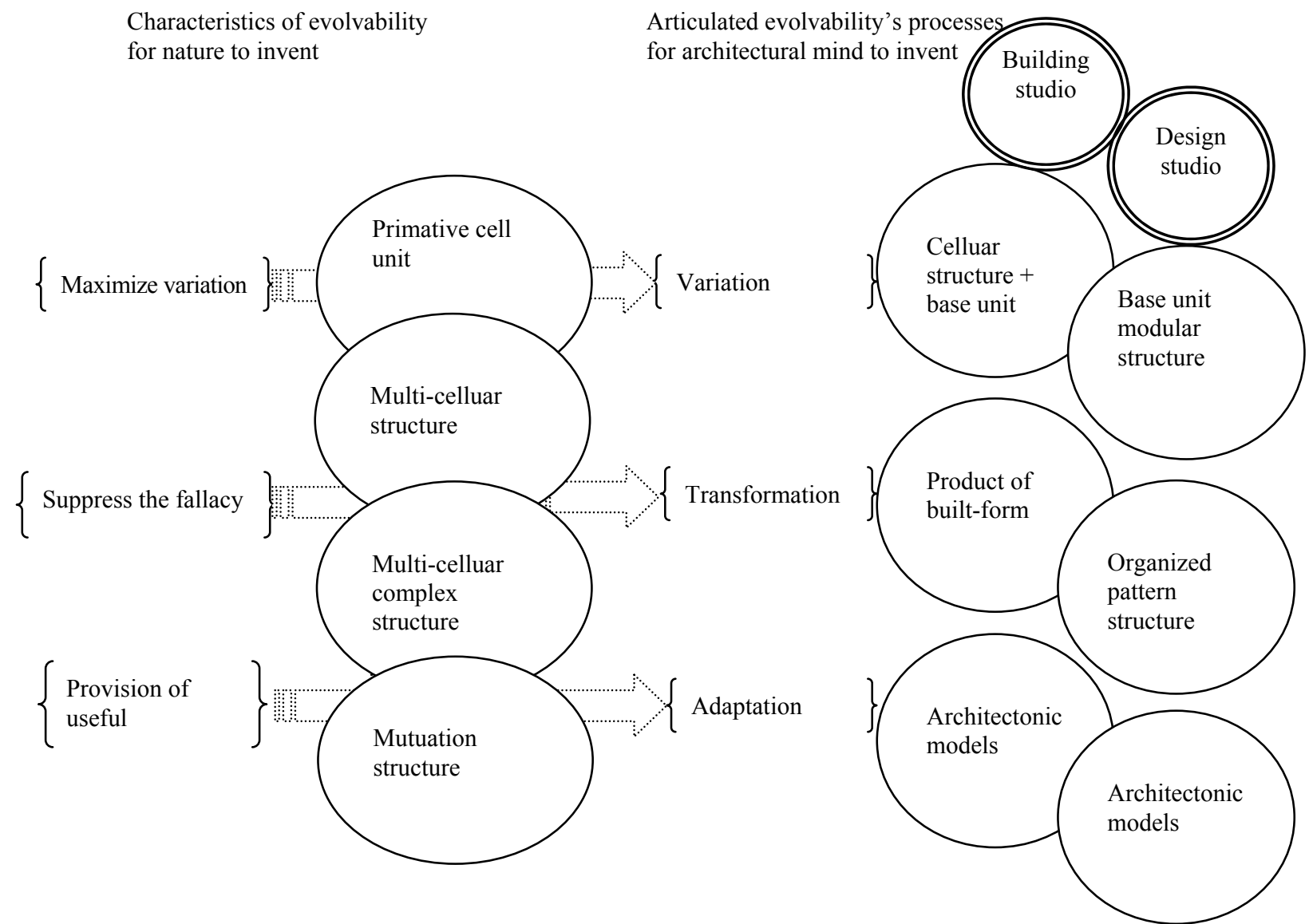

Fig. 2 Translation of natural novelty; the building and design studios are being integrated by articulation of evolvability's processes.

The teaching procedure generates answers within the organization of "operational" and "how-to-do" project's processes in order to set instruction's stage and come together under the guidelines of evolution strategy and preliminarily those have been given before. The wholeproject process is instructed to precede in strata from smallest to largest, simplest to most complex in order to emerge novelty.

The algorithm in meaning is not unfamiliar when it is just defined as a precise way of explaining how todo something. Beside that, well-known descriptionin Glossary of the New Mathematics of Architecture Burrys define the term as "a very specific set of instructions for carrying out a procedure that generally includes an instruction to stop" [9]. And they continue definition with the idea of an algorithm or programme as "a formal procedure predates the existence of electronic computers, but to use a computer always means to activate an algorithmic procedure that transforms input to output" [9]. Likewise, in sense of architecture thinking, the algorithm is required to map out "operation" and "how-to-do" process to jump start from nano to micro and macro scales with response of each studio outcomes. That also addresses the key challenges of innovation for material choice and detailing to organize of each relation beginning from the irreducible part. As applying the similar consideration in quest of "what will be done", the outcome product of the last studio assignment becomes the input product of next task to evolve.

Fig. 3 illustrates the frame-work of systematic in circular diagrams. The three subsetted circles have a common origin where each of diameter reduces from out to into focus. 


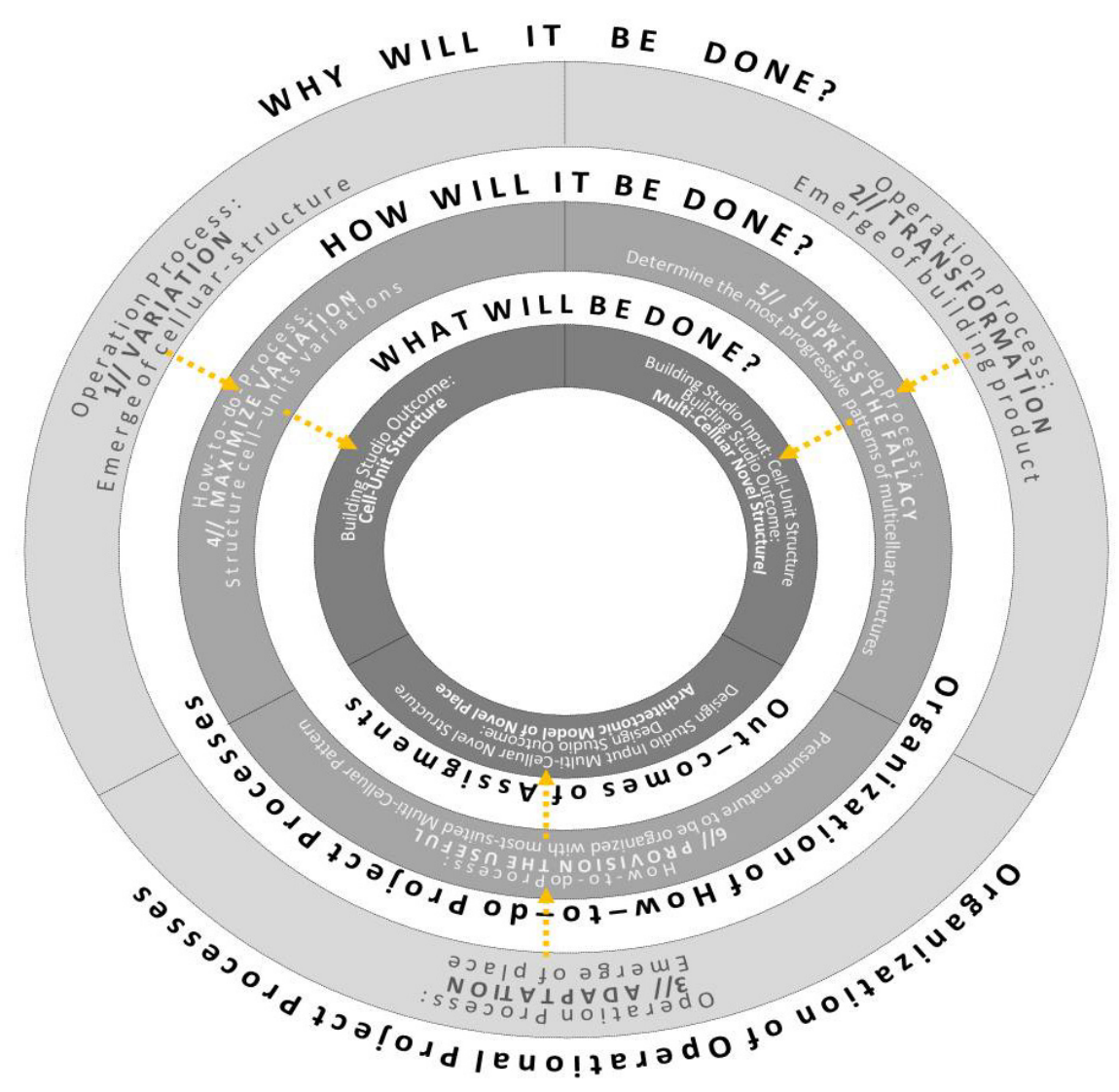

Fig. 3 Cycling Diagram of systematic frame-work.

The outermost circle frames the operational projects' processes as the goals of assignments, cycling in three circular segments are derived by the question "why will it be done?". The systematic cycles through how-to-do project processes and frames "how will it be done?" question of building studio. The systematicfinals at the innermost circle of "what will be done?" embed in the out-comes of assignments of building and design studios. It completes with the segment of design studio's outcome, where the novel structures of building studio are being transformed into an architectonic model of novel place.

The student-work of each process illustrating in Figs. 4 and 5 vertically flows through sequential diagrams of variation, transformation and adaptation. The act of tracing is deeply rooted in architectural profession. In Fig. 4, the line drawings are derived from the structural elements of module which generates multi-novel structure of transformation process. The ball nodes system of module is traced through the length of strut in order to articulate the angles between the struts in figurative display. Although the triangular cell units generate regular pentagon of geodesic triangle, structural contours are emerged random in these several figurative displays. These random contour lines evoke a creative inspiration to make a topographic model of a mutational place. The students transmit the flow of random contour, which is derived from their structural models to a macro-scale in design studio assignment. Hence, they track this flow to form the stacked strata of a geologic-emerge and reveal hybrid model with their natural environment.

Fig. 5 illustrates an alternative works of same students who had already made the previous one. Unlike the geodesic pentagonal structure, this model 
Unfolding Evolution Strategically in Integrated Studios of Building and Design to Innovative Grasp of Design Creativity
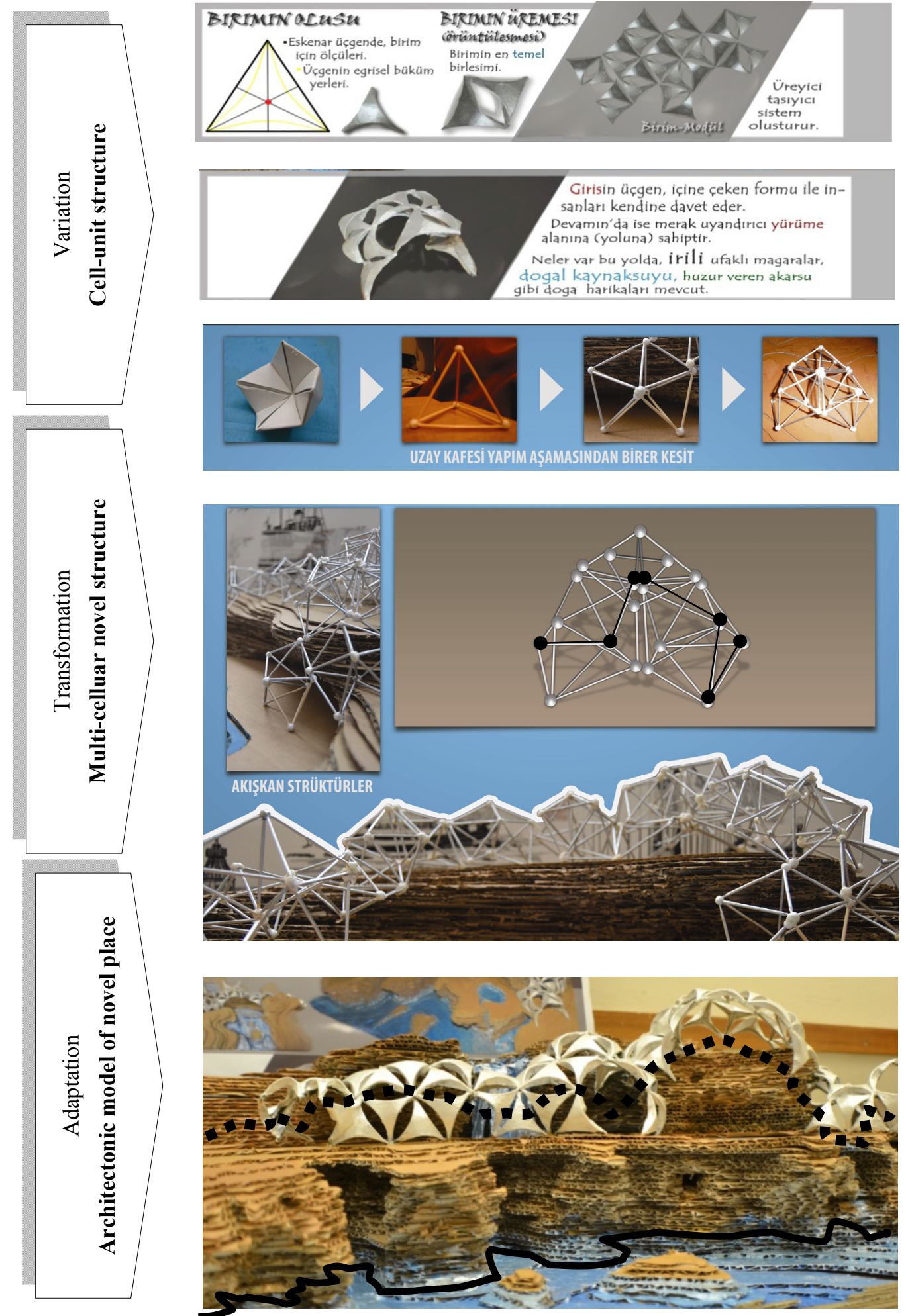

Fig. 4 Building and design studio works of Ilknur Ergin \& Cuneyd Karaaslan, integrated studiowork as one of the case-study for innovative grasp of design creativity. 


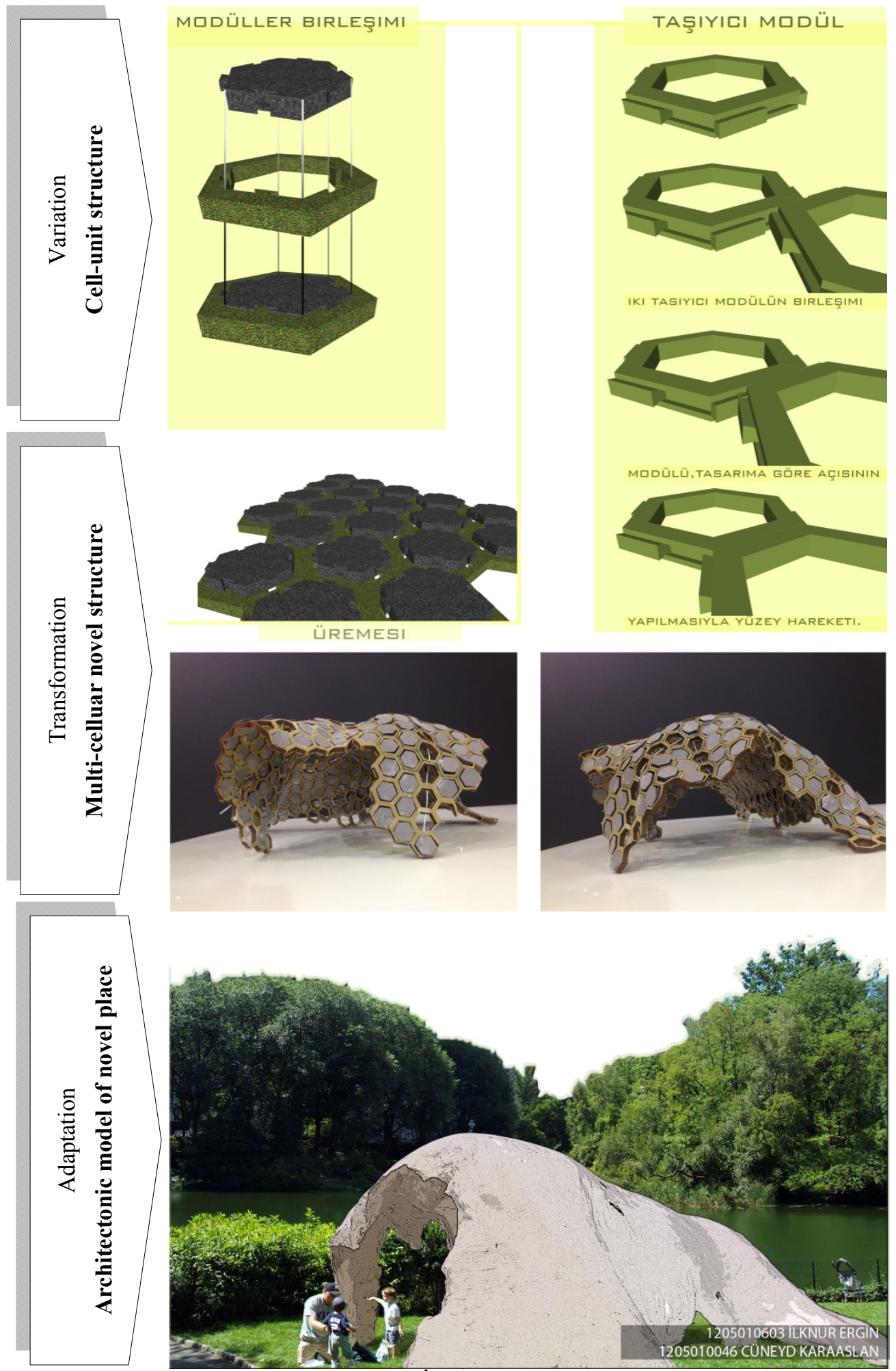

Fig. 5 Analternative building and design studio work of İlknur Ergin \& Cuneyd Karaaslan, integrated studio work as a hybrid-case study of previous work which is illustrated in Fig. 4. 
is distinguished with hexagonal interlocking structure. In this example, instead of random stacked slabs of previous tectonic model, the hexagonal structured canopy has been adapted to such a mutational morphology of planting. The scalar correlation is arranged between the spatial structure and tree planting of tectonic model place's flora.

\section{Conclusions}

Design has compromising strategy, diffused in large spectrum, where it lays between extreme thresholds of art and science thinking minds. That activates proposal professions with chief purpose to yield for any built-form. And the diversification of discipline designates them within the emergence scales of production. Although here, it is clearly subjected to human-made proceeding evolution (not human evolution but it is meant evolution of what made by human). Attempting to apply causality conjunction, this study relies on biological evolution, which is unfolded for internalization in building and design teaching. In this way, it is being proposed to clarify the complex crucial tasks for students and educators of design in order to grasp the key challenge of being innovative for each day. In this context, the organization of building and design projects' program is actualized in proceeding the nature's emergence scales of production. The proceeding was unfolded through primitive unit to multi-cellular novel organism and all-in-emerge cosmic constitution of place and so the production scales of evolution are mapped in those three thresholds' steps of emergence. They introduced operational processes which were defined as stated:

- Variation, identified with emergence of cellular structures;

- Transformation, identified with emergence of building products-the varied cellular structures transformed as modular units of spatial building products;

- Adaptation, identified with emergence of place - the architectural emergence were adopted with created provisional nature, as architectonic prototype.

The algorithm of conceptual framework in teaching could lead to evolve the capacity of design innovation. Inherently, the effective processing way of evolution strategy also defines cut-off way for students to grasp capacity to evolve. The biological evolvability was brought into strategy with three characteristics which were sought by Mark Kirschner. They facilitated the How-to-do processes of algorithm which are instructed as stated:

- Maximize variation in amount of cellular structures produced;

- Suppress the fallacy of produced structures for the most progressive patterns of multi-cellular novel forms;

- The provision of useful novel structures for the most-suited to the architectonic model of a novel place.

Tracing,mapping, notation and modelling as design methods are acts of transformation that are informed by various design parameters. These techniques are therefore a form of analog parametric designing the truest sense of word [10].

In building and design studios, project tasks are built to be much more productive to get novelty and the critical point in design-labour is to decide where to start. However, getting start on the derived forms of existing organisms were denied, their strategy guidelines to exist were called for evolvability in invention of novel form due to whatever was given as a task. Furthermore, the evolution strategy was used to integrate each studio of building and design project courses in a unique algorithm of teaching, as nature "how thinks-and-things get done".

\section{References}

[1] Leatherbarrow, D. 2012. "The Project of Design Research." In Design Innovation for the Built Environment Research by Design and the Renovation of Practice, edited by Hensel U. M. New York: Routledge. 


\section{Design to Innovative Grasp of Design Creativity}

[2] Moussavi, F. 2009. The Function of Form. Cambridge: Actar and Harvard University Graduate School of Design.

[3] Vincent, J. 2012. "How Can Biology Inform Architects?" In Design Innovation for the Built Environment Research by design and the Renovation of Practice, edited by Hensel U. M. New York: Routledge.

[4] Weinstock, M. 2010. The Architecture of Emergence: The Evolution of Form in Nature and Civilization. Minneapolis: John Wiley \& Sons.

[5] Jaeschke, A. 2006. "Environmental Intensifiers." Versatility and Vicissible 78 (2): $88-79$. doi:10.1002/ad.646.
[6] Kirschner, M. 2009. "Variations in Evolutionary Biology." In the Architecture of Variation, edited by Lars Spuy Broek. London: Thames \& Hudson.

[7] Reiser. J., and Umemoto, N. 2005. Atlas of Novel Tectonics. New York: Princeton Architectural Press.

[8] Delanda, M. 2009. "Material Evolvability and Variability." In the Architecture of Variation, edited by Lars Spuy Broek. London: Thames \& Hudson.

[9] Burry, J., and Burry M. 2012. The New Mathematics of Architecture. London: Thames \& Hudson.

[10] Mückenheim, M., and Demel, J. 2012. Inspiration Contemporary Design Methods in Architecture. Amsterdam: BIS Publishers. 